\title{
PREVALENCE OF ANTI-TOXOPLASMA GONDII ANTIBODIES IN ABORTED EWES IN KUWAIT By
}

\author{
MAHA S. H. ALAZEMI \\ Department of Criminal Evidences, Ministry of Interior, Kuwait \\ Abstract
}

Serum samples from 528 aborted ewes from different sheep flocks in Kuwait were tested for Toxoplasma gondii. The indirect hemagglutination test (IHAT) was used with a titer of 1:80 considered positive. Antibodies to T. gondii were found in $94(17.8 \%)$. The highest number of positive ewes $(23 ; 24.5 \%)$ had a titer of $1: 640$. Only one aborted ewe had a titer of $1: 2560$.

This study is the first to report Toxoplasma infection in sheep which may pose risk to humans who consume under cooked mutton. The detection of Toxoplasma antibodies in aborted ewes refers to the implication of toxoplasmosis in abortion among sheep in Kuwait.

Key words: Kuwait, Toxoplasmosis, Sheep, Abortion, IHAT

\section{Introduction}

Toxoplasma gondii is a protozoan parasite widespread all over the world. It is an increasing zoonosis of the worldwide distribution concern hazards in both human health and veterinary medicine. The disease is caused by an obligate intracellular protozoan parasite (Halonen and Weiss, 2013). Although the final host is the cat, $T$. gondii infects all mammals including man (Edwards and Dubey, 2013). The most common sources of human infection are ingestion of tissue cysts in raw meat or of food or water contaminated with oocysts shed by felids and transplacental transmission (Pfaff et al, 2014). It is a significant cause of abortion to livestock and domestic animals (Haridy et al, 2010). The parasite has significant impact not only on animal production but also on public health throughout the world (Sudan et al, 2013). This may pose a threat to farm animals, including sheep and goats as well as the farmers (Elsheikha, HM, Morsy, TA, 2009). Worldwide, about six billion people are infected with this parasite (Ferroglio et al, 2014).

The aim of this study was to carry out a preliminary study to explore the potential role of toxoplasmosis as a cause of abortion in sheep in Kuwait.

\section{Material and Methods}

A total of 528 blood samples were collected from the aborted ewes in different sheep flocks and sent in ice boxes to the laboratory where the sera were separated and stored at $-20^{\circ} \mathrm{C}$ until tested. Ewes, which lost their feti, were included in this study, but no other information was available regarding sex, age breed of sheep. Also, sheep were not tested for other diseases, which might cause abortion in these animals.

For determination $T$. gondii antibodies, sera were tested using indirect hemagglutination test (IHAT). The serologic testing was performed according to the manufacturer (Fumouze diagnostics, France). Sera were initially screened at 1:80 and 1:160 dilutions. Seropositive sera were end titrate using 4-fold dilutions. Sera with doubtful results were retested. Positive and negative controls as well as serum control were included in each test, whereas reagent control was set up only per assayed series.

\section{Results}

Using a titer of 80 as the criterion for being seropositive, antibodies to $T$. gondii were found in $94(17.8 \%)$ out of 528 sera of aborted ewes: in titers of 1:80 in 14, 1:160 in $21,1: 320$ in $25,1: 640$ in $23,1: 1280$ in 10 and 1:2560 in only one animal. 


\section{Discussion}

The estimated $T$. gondii seroprevalence rate of $17.8 \%$ in the aborted ewes in Kuwait was considerably lower than the estimated seroprevalence rate of the $92.3 \%$ and $51.7 \%$ reported by Sanad and Al-Ghabban (2007) for the samples of aborted ewes and goats respectively in Saudi Arabia using the same serological technique (IHAT). These marked differences are probably due to the source of samples. In the present study, the samples were representative from different various sheep flocks, while the samples used in the studies in Saudi Arabia were only from one flock of sheep or goats during an abortion outbreak. Although, the risk factors of toxoplasmasis on the sheep and goat farms was not mentioned, including the presence of cats, yet it seemed that these animals were frequently exposed to Toxoplasma oocysts. This was indicated by the high levels of antibody titers in the studies in Saudi Arabia where $22.8 \%$ and $28.6 \%$ of aborted ewes had titers of 1:1024 and 1:4069 respectively. High levels of IHAT antibody titers against $T$. gondii reflect an active infection (Silva et al, 1997).

For human, the diagnosis of abortion, stillbirth, premature labour, or neonatal death due to Toxoplasma infection needs careful and laborious evaluation. The use of ELISA (IgG \& $\operatorname{IgM})$ is a must, as it is more sensitive and specific than IHAT (Soliman et al, 2001).

This study refers to the potential risk implication of toxoplasmosis in abortion in sheep flocks in Kuwait; the situation which may have adverse effect on the development and reproduction of these animals. Also this study reports toxoplasmosis in food animals for the first time, the situation which could pose threat to the consumers of ill-cooked mutton. Antibodies to Toxoplasma have been reported in humans (Behbehani and AlKarmi, 1980; Iqbal and Khalid, 2007) as well as from desert rodent, Meriones crassus (Al-Karmi and Behbehani, 1980). Reporting of Toxoplasma antibodies in stray cats' sera and oocysts in their faeces indicate that cats contaminate the environment and are source of infection to humans and animals (Abdou et al, 2013).

Abroad, Morsy et al. (1994) in Riyadh reported antibodies in commensal rodents, and al Dakhil and Morsy (1996) detected natural Toxoplasma infection sought in the Indian grey mongoose (H. edwardsi, Greffroy, 1818) trapped in the eastern region, Saudi Arabia. Dubey et al. (2003) isolated Toxoplasma from chickens and ducks in Egypt and Barakat et al. (2012) proved the zoontoc role of chickens in transmission of toxoplasmosis. Besides, El Behairy et al. (2013) in Egypt isolated and characterized $T$. gondii from stray dogs. el-Moukdad (2002) in Syria reported sero-prevalence of Toxoplasma gondii in Awassi sheep. Abu-Dalbouh et al. (2012) reported ovine and caprine toxoplasmosis in aborted animals in Jordanian goat and sheep flocks.

Generally speaking, toxoplasmosis ranged from 7.5-95\% worldwide: $7.5 \%$ in Scotland (Jackson and Hutchinson, 1987), 22.5 up to $37.4 \%$ in Saudi Arabia (Shoura et al, 1973; Abbas et al, 1986), 50\% in USA (Stagno, 1980 ), $54.0 \%$ in Kenya (Griffin and Williams, 1983), 37.5\% in Libya (Kassem and Morsy, 1991), 47\% in Nigeria (Onadeko et al, 1992), 37\% in Jordan (Morsy and Michael, 1980), and 95.5\% in Kuwait (Behbehani and Al-Karmi, 1980).

On the other hand, Alonso et al. (1984) stated that patients with AIDS developed up to $50 \%$ cerebral toxoplasmosis. Bazaco et al. (2008) stated that to avoid nosocomial toxoplasmosis one of the duties the nurse is to offer well cooked meat and well washed green salad to the pregnant women to prevent them from acquiring toxoplasmosis and to delivery infants with congenital infection. Besides, $T$. gondii antibodies were reported in the Egyptian blood donors associated the risk factors for the blood transmission (Elsheikha et al, 2009). Anwar et al. (2013) reported that the presence of coenurosis and toxoplasmosis are serious parasitic problems that play a significant role in sheep management in Egypt, as a 
result of close contact between livestock and dogs and cats, which play a critical role in the life cycle of these parasites. Alanazi (2013) examined serum samples from 891 sheep, 555 goats and 182 camels slaughtered for food and human consumption from three main municipal abattoirs in Riyadh City. He concluded that $T$. gondii antibodies were wide-spread in the animal populations for human consumption and welfare, and that toxoplasmosis is a widely spread zoonotic infection. Moreover, the persistence of $T$. gondii in the raw sausages using in-house developed and validated real time-PCR, the $T$. gondii survived in relation to the rawsausage-manufacturing-process included the different ripening processes were reported (Abdulmawjood et al, 2014).

\section{Conclusion}

Toxoplasmosis is a common infectious protozoan disease of man and animals with worldwide zoological and geographical distribution including Kuwait. The outcome results showed that the $T$. gondii specific antibodies against sheep, and consequent the risk of acquiring toxoplasmosis by the consumption of the sheep meat and milk. Besides, acquired human toxoplasmosis is due to the contaminated sources such as fresh milk, home prepared cheese/sausage.

So, the health authorities must consider the integrated strategies, including efficient management measures for prevention and control $T$. gondii infection in sheep and no doubt other edible and stray animals. The implementation of the integrated control strategies as well as measures for prevention and control of $T$. gondii infection within edible animals is recommended.

The study of toxoplasmosis infection in edible animals rather than sheep in Kuwait is ongoing and will be published by the present author in due time.

\section{References}

Abbas, SA, Basalamah, A, Serebour, F, Alfonso, M, 1986: Toxoplasma gondii antibodies in Saudi women and outcome of congenital infection among new-borne in Saudi Arabia. Saudi Med. J. 7:346-54.

Abdou, N-E MI, Al-Batel, MK, El-Azazy, OME, Sami, AM, Majeed, AH, 2013: Enteric protozoan parasites in stray cats in Kuwait with special references to toxoplasmosis and risk factors affecting its occurrence. J. Egypt. Soc. Parasitol. 43, 2:303-14.

Abdulmawjood, A, Rosa, S, Taubert, A, Bauer, C, Failing, K, et al, 2014: Toxoplasma gondii in raw sausages using in-house developed and validated real time-PCR. Meat Sci. 97, 4: 542-7.

Abu-Dalbouh, MA, Ababneh, MM, Giadinis, ND, Lafi, SQ, 2012: Ovine and caprine toxoplasmosis (Toxoplasma gondii) in aborted animals in Jordanian goat and sheep flocks. Trop. Anim. Hlth. Prod. 44, 1:49-54.

Al Dakhil, MA, Morsy, TA, 1996: Natural Toxoplasma infection sought in the Indian grey mongoose (H. edwardsi, Greffroy, 1818) trapped in the eastern region, Saudi Arabia. J. Egypt. Soc. Parasitol. 26, 3:645-52.

Alanazi, AD, 2013: Determination of seropositivity for Toxoplasma gondii in sheep, goats and camels slaughtered for food and human consumptions in Riyadh municipal abattoirs, Saudi Arabia. J. Egypt. Soc. Parasitol. 43, 3:56976.

Al-Karmi, T, Behbehani, K, 1980: Epidemiology of toxoplasmosis in Kuwait. II. Toxoplasma gondii in the direst rodent, Meriones crassus. Trans. Roy. Soc. Trop. Med. Hyg. 74, 6: 745-6.

Al-Mufarrej, SI, Hussein, MF, Aljumaah, RS, Gar El-Nabi, AR, 2011: Toxoplasmosis in goats in Riyadh, Saudi Arabia. J. Anim. Vet. Adv. 10, 21:2779-82.

Alonso, R, Heiman, P, Mancall, EL, 1984: Cerebral toxoplasmosis in acquired immune deficiency syndrome. Arch. Neurol. 41:321-3.

Anwar, S, Mahdy, E, El-Nesr, KA, El-Dakhly, KM, Shalaby, A, et al, 2013: Monitoring of parasitic cysts in the brains of a flock of sheep in Egypt. Rev. Bras. Parasitol. Vet. 22, 3:323-30.

Barakat, AM, Salem, LM, El-Newishy, AM, Shaapan, RM, El-Mahllawy, EK, 2012: Zoonotic chicken toxoplasmosis in some Egyptians governorates. Pak. J. Biol. Sci. 15, 17:821-6.

Bazaco, MC, Albrecht, SA, Malek, AM, 2008: Preventing foodborne infection in pregnant women \& infants. Nurs. Women Hlth. 12, 1:46-55. 
Behbehani, K, Al-Karmi, T. 1980: Epidemiology of toxoplasmosis in Kuwait. I. Detection of antibodies to Toxoplasma gondii and percentage distribution among the inhabitants. Trans. Roy. Soc. Trop. Med. Hyg. 74, 2:209-12. Dubey, JP, Graham, DH, Dahl, E, Hilali, M, El-Ghaysh, A, et al, 2003: Isolation and molecular characterization of Toxoplasma gondii from chickens and ducks from Egypt. Vet. Parasitol. 114, 2:89-95.

Edwards, JF, Dubey, JP, 2013: Toxoplasma gondii abortion storm in sheep on a Texas farm and isolation of mouse virulent atypical genotype $T$. gondii from an aborted lamb from a chronically infected ewe. Vet. Parasitol. 192, 1/3:129-36.

EI Behairy, AM, Choudhary, S, Ferreira, LR, Kwok, OC, Hilali, M, et al, 2013: Genetic characterization of viable Toxoplasma gondii isolates from stray dogs from Giza, Egypt. Vet. Parasitol. 193, 1/3:25-9

El-Moukdad, AR, 2002: Serological studies on prevalence of Toxoplasma gondii in Awassi sheep in Syria. Berl. Munch Tierarztl. Wochenschr. 115, 5/6:186-8

Elsheikha, HM, Morsy, TA, 2009: Role of immune response in Toxoplasma gondii tachyzoite-bradyzoite stage interconversion: A Janus in determining disease outcome. J. Egypt. Soc. Parasitol. 39, 2:595-8.

Elsheikha, HM, El-Motayam, MH, Abouel-Nour, F, Morsy, AT, 2009: Oxidative stress and immune-suppression in Toxoplasma gondii positive blood donors: implications for safe blood transfusion. J. Egypt. Soc. Parasitol. 39, 2: 421-8 Ferroglio, E, Bosio, F, Trisciuoglio, A, Zanet, S, 2014: Toxoplasma gondii in sympatric wild herbivores and carnivores: epidemiology of infection in the Western Alps. Parasit Vectors 7, 1: 196. doi: 10.1186/1756-3305-7-196.

Griffin, L, Williams KA, 1983: Serological and parasitological survey of blood donors in Kenya for toxoplasmosis. Trans. Roy. Soc. Trop. Med. Hyg. 6:143-5.

Halonen, SK, Weiss, LM, 2013: Toxoplasmosis. Handb. Clin. Neurol. 114: 125-45.

Haridy, FM, Saleh, NMK, Khalil, HM, Morsy, TA, 2010: Anti-Toxoplasma gondii antibodies in working donkeys and donkey's milk in Greater Cairo, Egypt. J. Egypt. Soc. Parasitol. 40, 2:459-64.
Iqbal, J, Khalid, N, 2007: Detection of acute Toxoplasma gondii infection in early pregnancy by IgG avidity and PCR analysis. J. Med. Microbial. 56, 11:1495-9.

Jackson, M, Hutchinson, WM, 1987: A seroepidemiological survey of toxoplasmosis in Scotland and England. Ann. Trop. Med. Parasitol. 81:55-65.

Kassem, HH, Morsy, TA, 1991: The prevalence of anti-Toxoplasma antibodies among pregnant woman in Benghazi (S.P.L.A.J.), Libya. J. Egypt. Soc. Parasitol. 21, 1:69-74.

Morsy, TA, Michael, SA, 1980: Toxoplasmosis in Jordan. J. Egypt. Soc. Parasitol. 10, 2:457-70.

Morsy, TA, Sabry, AH, Habib, KS, Arafa, M A, el Bahrawy, AF, et al, 1994: Antibodies against Toxoplasma gondii in the commensal rodents trapped in Riyadh Region, Saudi Arabia. J. Egypt. Soc. Parasitol.24, 2: 279-84

Onadeko, MO, Joynson, DH, Payone, RA, 1992: The prevalence of Toxoplasma infection among pregnant women in Ibadan, Nigeria. J. Trop. Med. Hyg. 95:143-5.

Pfaff, AW, de-la-Torre, A, Rochet, E, Brunet, J, Sabou, M, et al, 2014: New clinical and experimental insights into Old World and neotropical ocular toxoplasmosis. Int. J. Parasitol. 44, 2:99-107.

Sanad, MM, Al-Ghabban, AJ, 2007: Serological survey on toxoplasmosis among slaughtered sheep and goats in Tabouk, Saudi Arabia. J. Egypt. Soc. Parasitol. 37, 1:329-40

Shoura, MA, Morsy, TA, EI Dasouqui, IT, 1973: Toxoplasmin skin tests in Riyadh, Saudi Arabia. J. Trop. Med. Hyg. 76, 10:254.

Silva, DA, Cabral, DD, Bernardina, BL, Souza, MA, Mineo, JR, 1997: Detection of Toxoplasma gondii-specific antibodies in dogs: A comparative study of immunoenzymatic, immunofluorescent and haemagglutination titers. Mem Inst Oswaldo Cruz. 92, 6:785-9.

Soliman, M, Nour-Eldin, MS, Elnaggar, HM, El-Ghareb, ME, Ramadan, NI, 2001: Toxoplasma antibodies in normal and complicated pregnancy. J. Egypt. Soc. Parasitol. 31, 2:637-46 Stagno, S, 1980: Congenital toxoplasmosis. Am. J. Dis. Child. 134: 635-7.

Sudan, V, Jaiswal AK, Shanker, D, 2013: Recent trends in the diagnosis of toxoplasmosis. Clin. Rev. Opinions 5, 2:11-7. 